http://jmscr.igmpublication.org/home/

ISSN (e)-2347-176x ISSN (p) 2455-0450

crossref DOI: https://dx.doi.org/10.18535/jmscr/v8i10.30

Journal Of Medical Science And Clinical Research

\title{
Ptosis-The Only Manifestation of Diabetic Neuropathy
}

\author{
Authors \\ Dr Biraja Prasad Beura ${ }^{1}$, Dr Purna Chandra Karua ${ }^{2}$ \\ ${ }^{1}$ (B.P.Beura), Post graduate Student, Department of Medicine, VIMSAR, Burla \\ ${ }^{2}$ (P.C.Karua), Associate Professor, Department of medicine, VIMSAR, Burla
}

\section{Introduction}

Diabetic neuropathy is one of the most common long-term complications of type 2 diabetes, Approximately $50 \%$ of patients with diabetes mellitus type I or type II will eventually develop neuropathy. ${ }^{[1-3]}$ The clinical presentation may be polyneuropathy, autonomic neuropathy, polyradiculopathies, or mononeuropathies, although many overlap syndromes occur.

While majority of such patients have distal symmetrical neuropathy, some patients develop focal and multi-focal neuropathies, including cranial nerve palsies.

The most common diabetic cranial mononeuropathies occur in those nerves which supply the extraocular muscles (III, VI and IV).

The involvement of the third nerve could be congenital or acquired in nature. The main causes of acquired third nerve palsy include: infections (CNS or local), trauma, direct or indirect compression of the nerve anywhere along its path, vascular conditions (ischemic/aneurysms), neoplastic, inflammatory or demyelinating diseases. $^{[4,5]}$

It could be complete or partial, pupil-sparing or involving, isolated or associated with other neurological symptoms.
It is important for the clinician to think about a wide variety of differential diagnoses in patients with diabetes presenting with cranial nerve palsy, as there are significant implications in treatment and prognosis depending on the cause.

Isolated superior division oculomotor nerve palsies are rare and generally result from structural lesions. ${ }^{[6]}$

We describe a patient with ptosis as the only manifestation of diabetic superior division oculomotor nerve palsy that recovered partially after the blood sugar was well-controlled.

The neurological examination revealed ptosis of the right upper eyelid. The pupils were equal and normally reactive. The extraocular movement and ocular alignment were normal. Other neurological examination revealed negative findings. During hospitalization, hyperglycemia with the glycated hemoglobin (10.9\%).

Brain magnetic resonance imaging showed no significant abnormalities. There was no clinical or laboratory evidence consistent with the diagnosis of myasthenia gravis, Lyme disease, syphilis, temporal arteritis, or other systemic vasculitis.

We controlled her blood sugar aggressively by regular insulin 14 units before each meal subcutaneous injections and tablet Metformin $500 \mathrm{mg}$ before breakfast. With intensive sugar 
control for 7 days, her blood sugar before discharge was $128 \mathrm{mg} / \mathrm{dL}$. After the hyperglycemia improved, the right side ptosis recovered partially within 1 week both subjectively and objectively. The diagnosis of diabetic oculomotor nerve palsy was made. Diabetes induced ischemic injury of nerve fibers innervating levator palpebrae superioris is the most possible cause.

\section{Case report}

A 57-year-old female presented to the emergency room of our hospital with acute onset right upper lid ptosis noticed 1 week ago. The patient reported the ptosis was progressive in course without diurnal change. The patient did not have blurred vision, headache, periorbital pain, focal numbness or weakness. There was no history of recent head trauma or any prodromal symptoms suggestive of a viral illness. She was suffering from type 2 diabetes mellitus without appropriate control. Her medication before admission included biphasic insulin 2 times a day but her compliance was poor. At the time of hospitalization her blood sugar was $337 \mathrm{mg} / \mathrm{dl}$. She was neither smoker nor alcoholic.

The brain computed tomography performed showed no intracranial lesion. On admission, the physical examination revealed no significant ophthalmological finding.

\section{Discussion}

Third nerve palsy typically manifests as diplopia and ptosis.

The classical presentation of oculomotor nerve palsy in diabetes is that of an acute onset diplopia with ptosis and pupillary sparing, this is due to the anatomical arrangement of the nerve fibers in the 3rd cranial nerve sbecause fibers controlling the pupillary reflex are superficial, thus spared from diabetic ischemia induced injury.

The oculomotor nerve separates into superior division and inferior division, with the superior division innervating the superior rectus and levator palpebrae superioris.
The diabetic 3rd nerve palsy may affect isolated superior or inferior division of the oculomotor nerve but diplopia usually exists. ${ }^{\text {[7-9] }}$

The nerve injury is thought to be caused by either nerve ischemia or infarction of the nuclei in the mesencephalon. In patients with diabetic oculomotor nerve palsy, infarction occurs in the core of the nerve, sparing the superomedial concentrated pupillomotor fibers and thereby pupil function, in contrast to palsies due to other diagnoses $^{[10,11]}$.

Diabetic oculomotor nerve palsies typically recover over weeks to months without sequelae.

Management is supportive, including optimal glycemic control as well as minimization of other risk factors for ischemia, including control of blood pressure and lipid levels ${ }^{[12]}$.

\section{References}

1. Tesfaye S, Boulton AJ, Dyck PJ, et al. Diabetic neuropathies: update on definitions, diagnostic criteria, estimation of severity, and treatments. Diabetes Care 2010;33:2285-93.

2. Standards of medical care in diabetes 2015: summary of revisions.Diabetes Care 2015;38 (Suppl): S4.

3. Edwards JL, Vincent AM, Cheng HT, et al. Diabetic neuropathy: mechanisms to management. Pharmacol Ther 2008;120:134.

4. Rush JA, Younge BR. Paralysis of cranial nerves III, IV and VI. Cause and prognosis in 1,000 cases. Arch Ophthalmol 1981; 99:76-9.

5. Richards BW, Jones FR, Younge BR. Causes and prognosis in 4,278 cases of paralysis of the oculomotor, trochlear, and abducens cranial nerves. Am J Ophthalmol 1992; 113:489-96.

6. Bregman DK, Harbour R. Diabetic superior division oculomotor nerve palsy. Case report. Arch Ophthalmol 1988;106: 1169-70. 
7. Keane JR. Third nerve palsy: analysis of 1400 personally-examined inpatients. Can J Neurol Sci 2010;37:662-70.

8. Chou KL, Galetta SL, Liu GT, et al. Acute ocular motor mononeuropathies: prospective study of the roles of neuroimaging and clinical assessment. $\mathbf{J}$ Neurol Sci 2004;219:35-9.

9. Greco D, Gambina F, Maggio F. Ophthalmoplegia in diabetes mellitus: a retrospective study. Acta Diabetol 2009; 46:23-6.

10. Keane JR. Third nerve palsy: analysis of 1400 personally-examined inpatients. Can J Neurol Sci 2010;37:662-670

11. Brown MR, Dyck PJ, McClearn GE, Sima AA, Powell HC, Porte D Jr. Central and peripheral nervous system complications. Diabetes 1982;31(Suppl. 1):65-70

12. Greco D, Gambina F, Maggio F. Ophthalmoplegia in diabetes mellitus. 